\title{
The Influence of Genital Mutilation on Women's Sexual Activities in Oke-Ona, Community, Abeokuta, Nigeria
}

\author{
Dare Ojo Omonijo ${ }^{1}$ \\ Michael C. Anyaegbunam ${ }^{2}$ \\ A. F. Chukwuemeka ${ }^{3}$ \\ Victoria Ajibola Adeleke ${ }^{4}$ \\ Olusola B. Okunlola ${ }^{5}$ \\ Ademolu Oluwaseun Adenuga ${ }^{6}$ \\ Elizabeth I. Olowookere ${ }^{7}$ \\ Olusegun Peter Olaoye ${ }^{8}$ \\ ${ }^{8}$ Chaplaincy Unit, Covenant University Ota, Nigeria
}

${ }^{1}$ Department of Student Industrial Experience Scheme (SIWES), Covenant University, Ota / Department of Sociology, Olabisi Onabanjo University, Ago-Iwoye, Nigeria

${ }^{2}$ Department of Psychology, Nnamdi Azikiwe University, Awka, Nigeria

${ }^{3}$ Department of Psychology, Nnamdi Azikiwe University, Awka, Nigeria

${ }^{4}$ Department of Student Affairs, Covenant University, Nigeria I

School of Law, University of KwaZulu-Natal, South Africa

${ }^{5}$ Department of Psychology, Covenant University, Ota, Nigeria

${ }^{6}$ Department of Sociology, Olabisi Onabanjo University, Ago-Iwoye, Nigeria

${ }^{7}$ Department of Psychology, Covenant University, Ota, Nigeria

Doi: 10.2478/jesr-2019-0044

\section{Abstract}

This study was conducted to examine the influence of female genital mutilation on women sexual activities in Oke-Ona community, Abeokuta North Local Government Area of Ogun-State, South-West Geopolitical Zone of Nigeria with respect to: sexual satisfaction, sexual desire and virginal penetration experience. In order to achieve its aim, the study raised three hypotheses, each on sexual satisfaction, sexual desire and virginal penetration experience. These hypotheses were tested through t-test statistical method via the Statistical Package for Social Sciences (SPSS) 23rd version. Results showed no positive interaction between genital mutilation and sexual satisfaction [t (109) $=.560, P>.05]$. It also revealed no significance in the mean difference frequency of sexual desire of genitally mutilated women compared to those not genitally mutilated [t $(109)=-.640, P>.05]$. Besides, the findings indicated no significant difference in the mean difference in the vaginal penetration experience between genitally mutilated women and those not genitally mutilated [t $(109)=-1.523, P>.05]$. Furtherance to the conclusions drawn, the implications of the findings were discussed and recommendations were made.

Keywords: Influence, Female, Genital Mutilation, Sexual Activities 


\section{Introduction}

Previous studies have shown that every society operates by its culture (Haferkamp \& Smelser, 1992; Valsiner, 2000; Omonijo, Olujobi, Anyaegbunam, Nnatu \& Adeleke, 2018; Pauliene, Diskiene \& Matuzeviciute, 2019). The concept of culture is the system of knowledge, meaning and action which has to do with beliefs, behaviour, substances and other features that a group of persons or groups of people within and outside a given locality share. (Bibeau \& Corin, 1995; Nastasi \& Hitchcock, 2016; Bonnie, Nastasi, Prerna, Arora \& Kris Varjas 2017; Bayeh \& Baltos, 2019)

Given this, it could be averred that culture is an essential aspect of life that is unique but its unique nature is restricted to each locality that makes a whole in a diverse society like Nigeria. However, when the unique nature of culture is considered, the differences in cultural practices come to bear among societies. However, in-spite of the differences, other studies have shown that culture is not static; it changes from time to time, most especially when it has contacts with internal and external forces. The internal forces could be via social change-revolution while external could be via acculturation (Antia, 2005; Alonso \& Álvarez, 2015).

Dwelling on Merriam Webster Dictionary (1928), acculturation is the cultural adjustment of a people or a group of people, who having gotten in contact with other people's culture, either through science and technology or migration (physical contact) compare their cultures with the new ones, cherish some of the new culture, see the reason the old cultures should be replaced with the new ones and decide to acclimatize to them for a new way of life. In other words, instead of such people disregarding the new culture by virtue of what some authors mostly in America and Britain refer to as ethnocentrism, they encourage their members to imbibe the new culture or mix the old culture with the new culture (Yiu, 2016) which some authors in French speaking countries regard as xenocentrism or assimilation.

Although, studies have shown that acculturation is as old as culture itself. It could be regarded as a continuous potency that enforces cultural dynamism with both negative and positive implications in different countries. In Africa, both the positive and negative implications of westernization have gained prominence in literature (Rostow, 1960; Frank, 1969; Warren, 1970; Rodney, 1972; Fanon, 1980). While authors have explored the positive impact of acculturation on Africans (Warren, 1980; Rostow, 1960), some others highlighted its negative implications on her rich cultural heritage (Frank, 1969; Fanon, 1970; Rodney, 1972). On the positive aspect, studies have shown that acculturation has resulted in termination of some barbaric customs and traditions in African societies. These include the killing of twins, burying the living with the dead, using cow dung to clean a new born baby's umbilical cord, human sacrifice, tribal facial marks, idol worshipping, wife inheritance, (Frater, 2007;Abasiekong, 2010; Abia, 2012; Ojua \& Omono 2012; Ojua, Ishor \& Ndom, 2013). While other studies have shown that strict adherence to the practice of concubinage, polygamy, betrothal, preference for male child, female denial of inheritance rights, education for example, are no longer endemic like in the recent past. On the negative side, scholars such as (Arowolo, 2010) contended that western culture has precariously contaminated the traditional value which Africans placed on integrity, hard work, decency etc. Kanu (2011) cited in Olu-Olu, 2017). The quest for materialism, irrespective of its sources has suddenly become the rave of the moment across Africa.

The foregoing shows that acculturation is a two sided concept which could be negative and positive; the combination of which could make acculturation a complex phenomenon to tackle among mankind. Therefore, it could be averred that it demands effective management by the leadership of every society largely because, the usefulness of the positive aspect of acculturation to societal development may not be easily ignored while the negative will continue to serve as impediments. It could therefore be averred that the inability to manage the negative and positive aspect of acculturation is the brain behind the persistence of most ancient negative cultural practices in many African societies, irrespective of their negative implications (Ojua, et al., 2013). One of such practices is female genital mutilation, which The World Health Organisation, (2008) and scholars such as Abdulcadir, Rodriguez and Say (2014), described as any practice that leads to the cutting of women genitalia, partially or total without any therapeutic prescription.

Although, Koski and Heymann (2017) have argued that the practice of female genital 
mutilation is becoming less common over time, but Teixeira \& Lisboa (2016) contends that the practice is still pervasive in developed and developing countries. Nevertheless, scholars such as Odukogbe, Afolabi, Bello and Adeyanju (2017) stated that the practice of female genital mutilation has been outlawed in the later, but Mpinga, Macias, Hasselgard-Rowe, Kandala, Felicien, Verloo, Bukonda and Chastonay (2016), have traced its continual practice in some of the developed nations to the resident immigrants. Koski and Heymann (2017) argued that the practice is still endemic in developing countries. Furthermore, Odukogbe, et al., (2017) attributed the persistent practice of female genital mutilation in developing countries such as African countries to sturdy socio-cultural effects.

Nigeria is one of the countries known for female genital mutilation with an estimated 1/3 (onethird) population of globally affected women (Okeke, Anyaehie \& Ezenyeaku, 2012). Studies have shown that its level of prevalence in the South-East, South-South and South-West geopolitical zones of Nigeria is at $77 \%, 68 \%$ and $65 \%$ respectively (Okeke et al., 2012; UNICEF, 2013; Adegoke, 2015). Reasons for holding to such cultural practice despite the campaign against it globally varies from one community to another (Nyarkoh, 2017), and it gives credence to the distinct nature of culture in human society (Malinowski, 1960). In the South-West, the study of Adetola (2017) revealed the prevalence of the act of cutting female clitoris in Owu, Gbadura and Oke-Ona communities in Abeokuta North Local Government Area of Ogun State, Nigeria, due to cultural relevance but the study failed to address issues relating to the influence of genital mutilation on women sexual activities. The present study limits its scope to Oke-Ona community based on its proximity to the location of one of the researchers who coordinated distribution and retrieval of questionnaires from the respondents.

\subsection{Statement of the Problem}

Several studies have explored the implications of indulging in female genital mutilation in both developed and developing countries (Shabila, Saleh, \& Jawad, 2014). While scholars such as Catania, Abdulcadir, Puppo, Baldaro, Abdulcadir and Abdulcadir (2007) have explored its strong connection with violation of women human rights, (Berg, Underland, \& Odgaard-Jensen, 2014;Banks, Meirik, \& Farley, 2006), which have expressed its negative medical implications on women. These include greater risks of hostile obstetric results, caesarean section and postpartum haemorrhage inclusive (Berg, et al., 2014).

Further to the above, Akinsulure-Smith and Chu, (2017) highlighted tortures associated with female genital mutilation to include pains or agony, bleeding, swelling etc. Also, studies have shown that women who have undergone genital mutilation are prone to high rates of post-traumatic stress, anxiety and other mental health disorders (Behrendt \& Moritz, 2005; Kizilhan, 2011; Knipscheer, Vloeberghs \& Kwaak, 2015). In another development, the work of Cook, Dickens and Fathalla (2002) indicated that female genital mutilation reduces female desire for sex and the probability of experiencing pre-marital or extra-marital sexual relationships.

Dwelling on the above, it could be observed that areas related to human rights, medical implications of the female genital mutilation, and social aspects of engagement have been fully expressed in literature, while issues relating to culture were clearly ignored. The possibility of genital mutilation inflicting adverse cultural, ritual, psychophysical impact on women is also crucial and should not have been neglected. Adetola, (2017) addressed these issues in his study on female genital mutilation in three communities in Abeokuta North Local Government of Ogun State (Owu, Gbagura and Oke-Ona llewo). With respect to cultural practice, Adetola, (2017) came up with the following reasons for holding on to female genital mutilation in the above three communities: strict obedience to the tradition handed over to the indigenes of these communities by their ancestors; the practice is being used to confirm whether a child is a bastard or not in these communities; disobedience to female genital mutilation is perceived to have serious negative social implications such as barrenness.

Although Adetola (2017) explored the cultural and social reasons for indulging in female genital mutilation in these communities, the study failed to ascertain the influence of genital mutilation on (i) sexual satisfaction; (ii) the frequency of sexual desire; and (iii) vaginal pains during 
sexual intercourse. Therefore, one is left with thoughts and questions surrounding the influence of genital mutilation on female sexual satisfaction, frequency of sexual desire and vaginal penetration in the course of sexual activity. In a bid to bridge this gap, the current study focused on women of Oke-Ona community, Abeokuta North Local Government Area of Ogun State, where the practice of female genital mutilation is prevalent.

The proposed influence of genital mutilation on women's sexual activities is illustrated in the conceptual model in Fig.1.

\section{Conceptual Model}

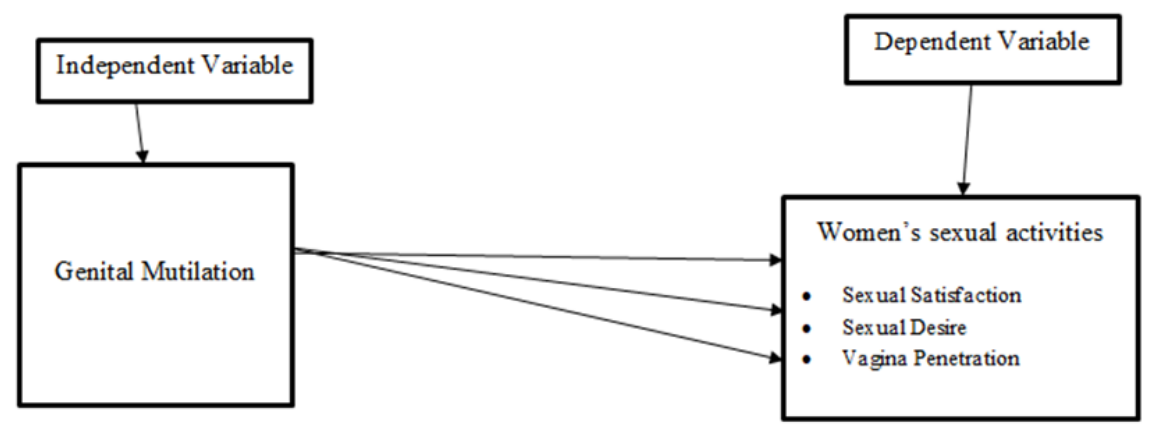

Fig.1: Research model showing the influence of genital mutilation on women's sexual activities

Based on the conceptual model, the main aim of this study is to examine the influence of genital mutilation on women sexual activities. Furtherance to this, the specific objectives of the study, the research questions and hypotheses raised were highlighted.

\subsection{Research Objectives}

The specific objectives of the study are as follows:

1. To establish the influence of genital mutilation on sexual satisfaction

2. To ascertain the influence of genital mutilation on frequency of sexual desire.

3. To determine the influence of genital mutilation on vaginal penetration

\subsection{Research Questions}

The following questions guided this study:

1. To what extent does genital mutilation significantly influence sexual satisfaction?

2. What influence does genital mutilation have on frequency of sexual desire?

3. What influence does genital mutilation have on vaginal penetration?

\subsection{Research Hypotheses}

For statistical analyses, the following hypotheses were drawn:

$\mathrm{H}_{1}$ : Female genital mutilation will significantly influence sexual satisfaction

$\mathrm{H}_{2}$ : Female genital mutilation will significantly influence frequency of sexual desire

$\mathrm{H}_{3}$ : Female genital mutilation will significantly influence vaginal penetration

\section{Methods}

Study Design-This study employed survey design because it gives room for little or no subjectivity. In this regard, the researcher may not have an opportunity to be biased in his or her findings. Also, the design encourages accurate result, among other things. 
Study Area-The study was restricted to Oke-Ona in Abeokuta North Local Government Area of Ogun-State, South-West, Nigeria. Abeokuta is the capital city of Ogun State and an Egba kingdom in Yoruba land, South-West Geo-Political Zone of Nigeria. It has two local government areas, i.e., Abeokuta South and Abeokuta North Local Government Areas (Ajisafe, 1972). The community under study is located within the Northern part of the state. The two local government areas serve as Ogun Central Senatorial District of Nigeria (Atanda, 1980).

Abeokuta, in respect of its geography and economy, is located within latitude. $7^{\circ} 9^{\prime} 39^{\prime \prime} \mathrm{N}$ and longitude $3^{\circ} 20^{\prime} 54^{\prime \prime} \mathrm{E}$ (Hoiberg, 2010). Moreover, the city is situated along the east bank of river Ogun with neighbouring forest savanna. Abeokuta covers a widespread area, encircled by mud walls of eighteen miles. Farm products such as rubber, rice, yam, cocoa, kolanut, maize, cassava, etc. are found in Abeokuta through farming activities. These agricultural products serve as a means of livelihood for farmers, local and foreign business persons in the metropolis.

Abeokuta is also known for tourism. The presence of Olumo rock in the city has attracted tourists from various parts of the country. Many artists in the theatre industry and musicians in the music industry more often than not, dramatize their plays and record their music in Olumo rock. In terms of education, Abeokuta has many primary, post-primary and tertiary institutions.

Study Population and Sample Size-According to the population census of 2006, the population of three communities out of which Oke-Ona is located is one million, two hundred and twenty-five thousand and fifty-two persons $(1,225,052)$ (National Population,2006). In determining the study sample size, the assumed population of Oke-Ona calculated through Yamane formula of (1967) was adopted (see Table 1).

Table 1: Community, Population, Proportion and Sample Size

\begin{tabular}{clccc}
\hline SN & Community & Population & Proportion & Sample Size \\
\hline 1 & Owu & 2000 & $400(2000) / 4,500$ & 178 \\
2 & Oke-Ona & 1500 & $400(1500) / 4,500$ & 133 \\
3 & Gbagura & 1000 & $400(1000) / 4,500$ & 89 \\
\hline & Total & $\mathbf{4 , 5 0 0}$ & & $\mathbf{4 0 0}$ \\
\hline
\end{tabular}

Source: Researcher's compilation

Yamane formula of (1967) is indicated below:

$$
n=\frac{N}{N \text { plus } N e^{2}}
$$

In this formula,

$\mathrm{N}$ is equal to the population size (2000)

$\mathrm{n}$ is equal to the sample size, which is expected to be determined with this calculation

$\mathrm{e}$ is equal to the level of significance $=5 \%$

Sampling Procedure- Multi-stage probability technique was employed to select respondents from Oke-Ona community. This technique involves the use of many methods which include: proportionate, simple random and purposive sampling techniques. First and foremost Oke-Ona was divided into thirteen clusters, each cluster was divided into ten (10) streets and ten houses were randomly selected via balloting. In each household, one respondent was randomly selected via balloting. The selected respondents were given the questionnaires designed for the study to fill.

Nine research assistants assisted the researcher to distribute and retrieve the questionnaires from respondents. As indicated in Table 2, the total of One Hundred and Thirteen (113) questionnaires were distributed to the respondents by the research assistants out of which only One Hundred and Twelve (112) were retrieved from respondents for analysis.

Method of Data Collection-This study engaged primary source of data collection, hence questionnaires were used to obtain information from respondents.

Description of Instruments-The Female Sexual Function Index otherwise known as the Multi-Dimensional Self-Report Instrument for Assessing Female Sexual Function designed by Rosen, Brown, Heiman, Leiblum, Meston, Shabsigh and Ferguson (2000) was adopted for this study. The instrument was modified to suit the purpose of this study. The instrument originally 
contains nineteen (19) questions but after its modification, they were increased to twenty-one (21). The questionnaire has the following three sections:

Table 2: Sections of the Study's Questionnaire

\begin{tabular}{lll}
\hline S/N Sections & Contents \\
\hline 1 & $\begin{array}{l}\text { Section } \\
\text { A }\end{array}$ & $\begin{array}{l}\text { This section contains the researcher's letter of introduction to respondents informing them } \\
\text { the purpose of the instrument and assuring them of the confidentiality of information } \\
\text { soliciting for. }\end{array}$ \\
\cline { 2 - 3 } 2 & $\begin{array}{l}\text { Section } \\
\text { B }\end{array}$ & $\begin{array}{l}\text { This section contains respondents' bio-data, year of marriage, marital status, level of } \\
\text { education, occupation and religion. The item on the year of marriage had four options while } \\
\text { item } 2 \text { which have to do with respondents' level of education had seven (7) options. The } \\
\text { item on occupation had seven (7) options while the item on marital status, and religion had } \\
\text { six (6) and four (4) items respectively. }\end{array}$ \\
\hline $\begin{array}{l}\text { Section } \\
\text { C }\end{array}$ & $\begin{array}{l}\text { This section contains information on whether respondents' genital mutilation was mutilated } \\
\text { or not. It contains two options (Yes or No) }\end{array}$ \\
\hline $\begin{array}{l}\text { Section } \\
\text { D }\end{array}$ & $\begin{array}{l}\text { This section had twenty-one questions. The instruments for the study include 6-item Sexual } \\
\text { Satisfaction Scale (SSS), 12-item Sexual Desire Scale (SDS) and the 3-item Vaginal }\end{array}$ \\
& $\begin{array}{l}\text { Penetration Experience Scale (VPES) developed by Rosen, et al., 2000) and modified by } \\
\text { the researcher. }\end{array}$ \\
\cline { 2 - 3 } &
\end{tabular}

Source: Field Work, 2019

Distribution of Questionnaire and Response Rate-The total of One Hundred and Thirteen (113) questionnaires were distributed to the respondents by the research assistants out of which only One Hundred and Twelve (112) were retrieved from respondents for data analysis.

Table 3: Questionnaire Distribution and Return Rate

\begin{tabular}{clcc}
\hline SN & Items & Frequency & $\%$ \\
\hline 1 & Questionnaires retrieved & 112 & 84.2 \\
2 & Unreturned questionnaires & 21 & 15.8 \\
3 & Questionnaires distributed & 133 & 100 \\
\hline
\end{tabular}

Source: Field Work, 2019

Validity and Reliability of Research Instruments-In order to determine the validity of the study instruments, content and construct methods of validition were employed. The use of content validity in a study of this nature becomes essential so as to indicate whether the research instrument properly covers all dimensions (objectives) of the study or not. To this end, experts in the area of study were consulted to assess the appositeness of each item of the instrument by looking at it and making constructive comments. These comments were used to revise the instruments before distribution. Moreover, comments from co-authors, supervisor and coordinator were found useful in obtaining final items. The study also considered the use of construct validity useful because it shows how an instrument adequately measured meaning of concept and construct. In order to achieve this, questions that appeared difficult to understand or vague and those that did not induce meaningful responses in the pilot study were amended.

In determining the reliability of study instruments, Cronbach Alpha was adopted as parameter for measurement. A suitable and conventional reliability coefficient of any study must be equal to or greater than 0.70 (Lee et al., 2017). In the present study the reliability coefficient for sexual desire, sexual satisfaction and pain during virginal penetration are $.94, .86, .91$ respectively. These are indicated below. 


\subsection{Scale: Sexual Desire}

Case Processing Summary

\begin{tabular}{|ll|c|c|}
\hline & $\mathrm{N}$ & $\%$ \\
\hline \multirow{3}{*}{ Cases } & Valid & 110 & 98.2 \\
& Excluded $^{\mathrm{a}}$ & 2 & 1.8 \\
& Total $^{*}$ & 112 & 100.0 \\
\hline
\end{tabular}

a. Listwise deletion based on all variables in the procedure.

Reliability Statistics

\begin{tabular}{|c|c|}
\hline Cronbach's Alpha & N of Items \\
\hline .937 & 12 \\
\hline
\end{tabular}

\subsection{Scale: Sexual Satisfaction}

Case Processing Summary

\begin{tabular}{|ll|c|c|}
\hline & & $\mathrm{N}$ & $\%$ \\
\hline \multirow{3}{*}{ Cases } & Valid & 102 & 91.1 \\
& Excluded $^{\mathrm{a}}$ & 10 & 8.9 \\
& Total & 112 & 100.0 \\
\hline
\end{tabular}

a. Listwise deletion based on all variables in the procedure.

Reliability Statistics

\begin{tabular}{|c|c|}
\hline Cronbach's Alpha & N of Items \\
\hline .861 & 6 \\
\hline
\end{tabular}

\subsection{Scale: Vaginal Penetration}

\section{Case Processing Summary}

\begin{tabular}{|ll|c|c|}
\hline & & $\mathrm{N}$ & $\%$ \\
\hline \multirow{3}{*}{ Cases } & Valid & 111 & 99.1 \\
& Excluded $^{\mathrm{a}}$ & 1 & .9 \\
& Total & 112 & 100.0 \\
\hline
\end{tabular}

a. Listwise deletion based on all variables in the procedure.

Reliability Statistics

\begin{tabular}{|c|c|}
\hline Cronbach's Alpha & N of Items \\
\hline .910 & 3 \\
\hline
\end{tabular}

\begin{tabular}{|ll|c|c|}
\hline & & $\mathrm{N}$ & $\%$ \\
\hline \multirow{3}{*}{ Cases } & Valid & 98 & 87.5 \\
& Excluded $^{\mathrm{a}}$ & 14 & 12.5 \\
& Total & 112 & 100.0 \\
\hline
\end{tabular}

a. Listwise deletion based on all variables in the procedure.

\section{Reliability Statistics}

\begin{tabular}{|c|c|}
\hline Cronbach's Alpha & N of Items \\
\hline .893 & 27 \\
\hline
\end{tabular}

The instruments for the study include 6-item Sexual Satisfaction Scale (SSS), 12-item Sexual Desire Scale (SDS) and the 3-item Vaginal Penetration Experience Scale (VPES) developed by 
Rosen, et al., (2000). The reliability coefficients for the instruments are .86, .94 and .94 respectively.

Ethical Considerations-The principles that govern research were observed, thus, respondents were properly briefed about the study and what it intends to achieve. All ethical standards with regards to anonymity and confidentiality were strictly observed by the researchers and assistants in collecting the data. Informal consent in written and verbal form was obtained from all the respondents

\section{Data Analysis}

To measure female genital mutilation, respondents were asked to indicate if their genitals were mutilated or not. The result in Table 4 shows that $94.6 \%$ of respondents had their genitals mutilated while just $4.5 \%$ did not.

Table 4: Respondents by Genital Mutilation

\begin{tabular}{clcc}
\hline SN & Genitally Mutilated & Frequency & Percentage \\
\hline 1 & Yes & 106 & 94.6 \\
2 & No & 05 & 4.5 \\
3 & No response & 01 & 0.9 \\
Total & & $\mathbf{1 1 2}$ & $\mathbf{1 0 0}$ \\
\hline
\end{tabular}

Source: Field work,(2019)

The result in Table 4 was illustrated in bar chart 1 below

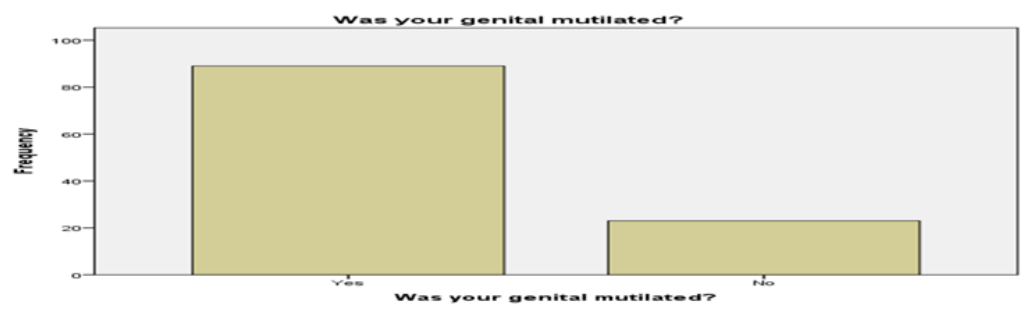

Bar-Chart 1: Respondents by Genital Mutilation

3.1 Analysis of Biographic data of respondents

Respondents' biographic data in this study were analyzed and interpreted below:

Table 8: Distribution of Biographical Data of the Respondents

\begin{tabular}{lcc}
\hline \multirow{2}{*}{ Characteristics } & \multicolumn{2}{c}{$\mathrm{N}=112$} \\
\cline { 2 - 3 } & Frequency & Percentage \\
\hline Kindly indicate your year of marriage. & 14 & 12.5 \\
Single & 41 & 36.6 \\
Less Than 10 Years & 32 & 28.6 \\
Above 10 years but not up to 20 years & 25 & 22.3 \\
20 years and above & 9 & 8 \\
\hline Kindly indicate your level of education & 23 & 20.5 \\
No formal education & 21 & 18.8 \\
Primary Education & 24 & 21.4 \\
Ordinary Diploma & & \\
Higher Diploma & &
\end{tabular}




\begin{tabular}{lcc} 
B.Sc. & 20 & 17.9 \\
MSc & 11 & 9.8 \\
PhD & 4 & 3.6 \\
\hline Kindly indicate youroccupation & & \\
Trading & 19 & 17 \\
Farming & 18 & 16.1 \\
Civil Servant & 32 & 28.6 \\
Clergy & 7 & 6.3 \\
Applicant & 9 & 8 \\
Student & 17 & 15.2 \\
Artisan & 10 & 8.9 \\
\hline Kindly indicate your marital status & & \\
Single & 15 & 13.4 \\
Married & 61 & 54.5 \\
Divorce & 10 & 8.9 \\
Widow & 7 & 6.3 \\
Separated & 15 & 13.4 \\
Widower & 4 & 3.6 \\
\hline Please, indicate your religion & & \\
Christianity & 52 & 47.7 \\
Islam & 40 & 36.7 \\
Traditionalist & 10 & 9.2 \\
Others & 7 & 6.4 \\
\hline
\end{tabular}

Source: Field survey, 2019

\subsection{Interpretations}

The percentage distribution of the respondents according to their socio-demographic characteristics indicates that the bulk (36.6\%) of respondents have spent less than 10 years in their marriages, $28.6 \%$ have spent between 10 to 20 years in marriage while $22.3 \%$ have spent over 20 years in their respective marriages.

A cursory look at their educational level shows that bulk $(21.4 \%)$ of the women possessed Higher National Diploma, followed by $20.5 \%$ of the women who only had primary education.

According to the result from the table, a large percentage of women in the study are $(28.6 \%)$ civil servants, $17 \%$ of the women were into trading activities, while $16.1 \%$ were farmers.

Also a bulk percentage $(54.5 \%)$ of the women are married, which means that almost 2 out of every four (4) women interviewed were married, $8.9 \%$ are divorced and $13.4 \%$ are single and separated respectively.

The percentage distribution of the women according to their religion indicated that a large percentage $(47.7 \%)$ of respondents are Christians, $36.7 \%$ are Muslims while only $9.2 \%$ of the respondents are traditionalists.

The data above were further illustrated through bar charts presented below:

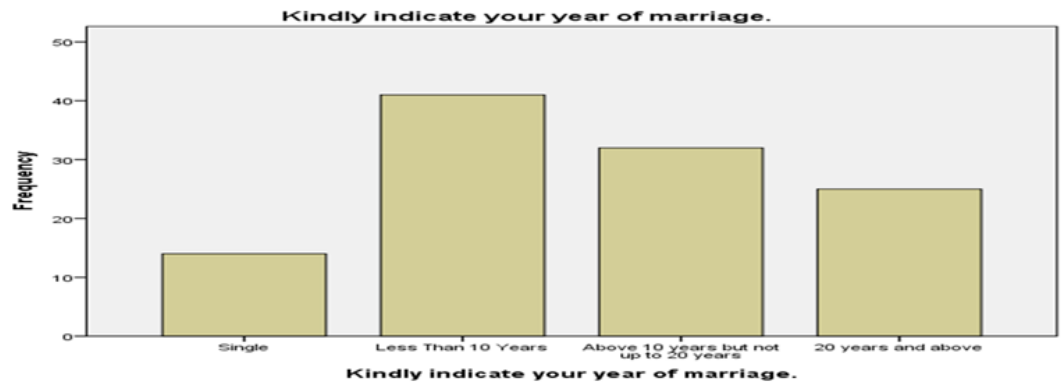

Chart 2: Respondents by year of marriage 


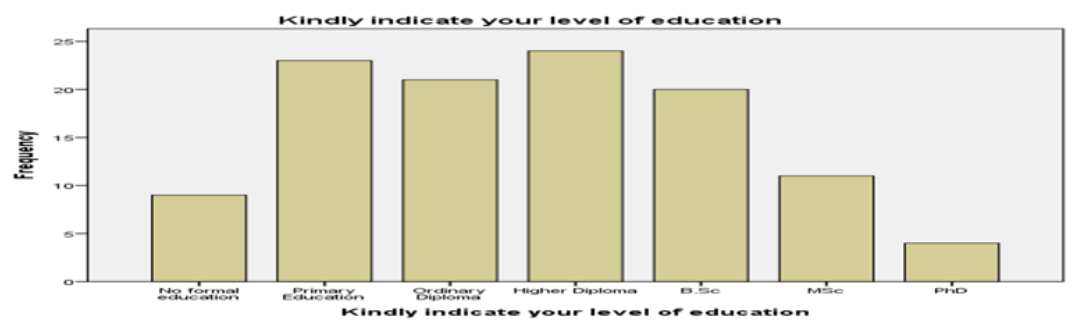

Bar Chart 3- Respondents by their level of education.

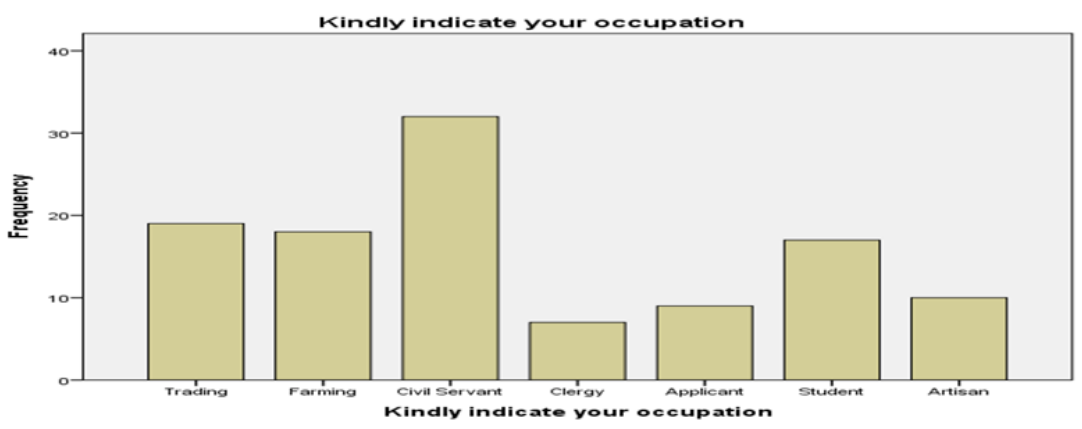

Bar-Chart 4: Respondents their occupation

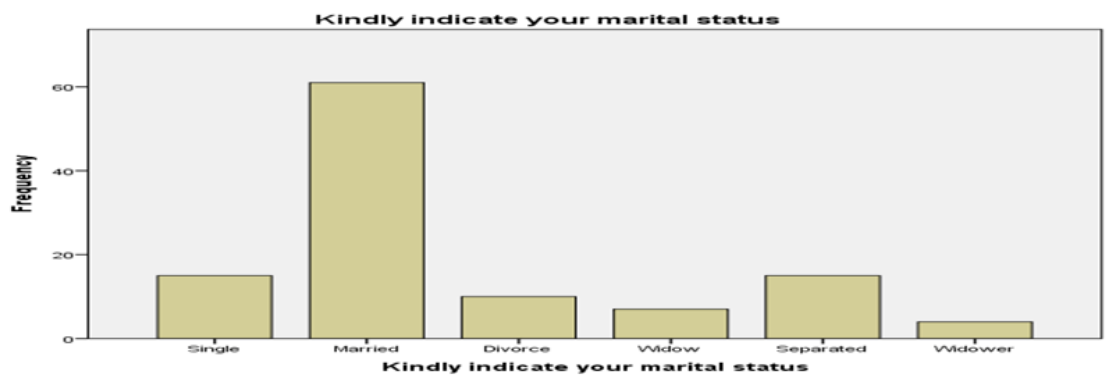

Bar-Chart 5: Respondents by Marital Status

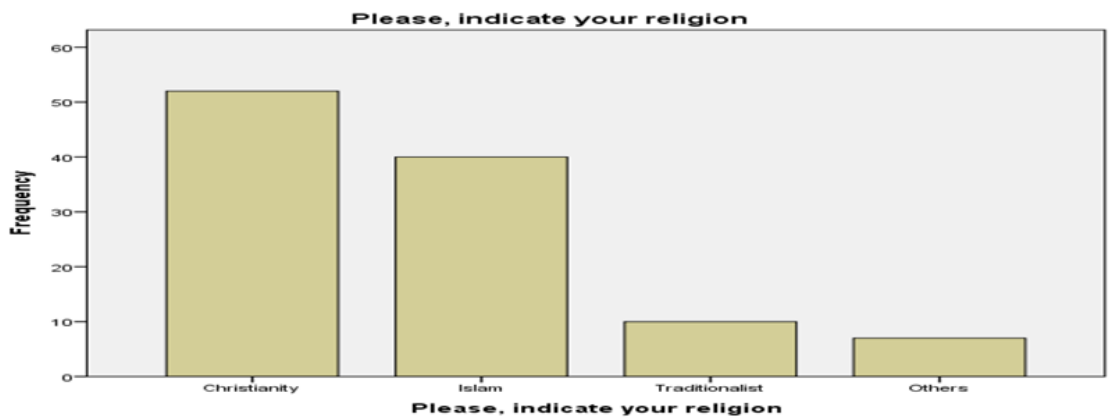

Bar-Chart 6: Respondents by Religion. 


\subsection{Testing of Hypotheses}

Based on the background to the study and the research questions, the following hypotheses were drawn for analysis and analyzed.

$\mathrm{H}_{1}$ : Genitally mutilated women will significantly differ in sexual satisfaction compared to their non-genital mutilation counterparts.

$\mathrm{H}_{2}$ : There will be significant difference in frequency of sex of genitally mutilated women compared to their non-genital mutilation counterparts.

$\mathrm{H}_{3}$ : Genitally mutilated women and those not genitally mutilated will significantly differ in pain in vaginal penetration during sexual intercourse.

\subsubsection{Hypothesis One}

Table 9: T-test for independent samples showing the difference in sexual satisfaction between genitally mutilated women and those not genitally mutilated

\begin{tabular}{lcccccc}
\hline & $\mathrm{N}$ & $\bar{x}$ & $\mathrm{SD}$ & $\mathrm{df}$ & $\mathrm{T}$ & $\mathrm{P}$ \\
\hline Genitally mutilated & 106 & 36.18 & 12.08 & \multirow{2}{*}{109} & \multirow{2}{*}{560} & \multirow{2}{*}{$>05$} \\
Not genitally mutilated & 5 & 33.00 & 19.14 & & & \\
\hline
\end{tabular}

Hypotheses one, which states that genitally mutilated women will significantly differ in sexual satisfaction compared to their non-genital mutilation counterparts, was not confirmed based on the result of t-test for independent samples in Table 9. The result showed the mean difference in the sexual satisfaction of genitally mutilated women and those not genitally mutilated. It revealed no significance difference in sexual satisfaction of genitally mutilated women compared to those not genital mutilated $[t(109)=.560, P>.05]$. This means that genital mutilation do not significantly influence sexual satisfaction which negates the submission of Osinowo and Taiwo, (2003) who found that uncircumcised women significantly reported better sexual functioning and marital satisfaction than the circumcised women $(t=9.4, d f=97, p<.01)$, thus confirming the presence of psycho-sexual dysfunction among the circumcised women.

\subsubsection{Hypothesis Two}

Table 10: T-test for independent samples showing the difference in frequency of sexual desire between genitally mutilated women and those not genitally mutilated

\begin{tabular}{lcccccc}
\hline & $\mathrm{N}$ & $\bar{x}$ & $\mathrm{SD}$ & $\mathrm{df}$ & $\mathrm{T}$ & $\mathrm{P}$ \\
\hline Genitally mutilated & 106 & 19.38 & 7.34 & \multirow{2}{*}{109} & \multirow{2}{*}{-.640} & \multirow{2}{*}{$>.05$} \\
Not genitally mutilated & 5 & 20.60 & 12.40 & & & \\
\hline
\end{tabular}

Hypotheses two, which states that there will be a significant difference in frequency of sexual desire of genitally mutilated women compared to their non-genital mutilation counterparts, was not confirmed based on the result of t-test for independent samples in Table 10. The result showed the mean difference in the frequency of sexual desire of genitally mutilated women and those not genitally mutilated. It revealed no significance difference in frequency of sexual desire of genitally mutilated women compared to those not genital mutilated [t $(109)=-.640, P>.05]$. This means that genital mutilation did not significantly influence how often women crave for sex confirming the findings of Berg and Denision, (2012) which says that genitally mutilated women are more likely to experience reduced sexual desire than genitally mutilated women. 


\subsubsection{Hypothesis Three}

Table 11: T-test for independent samples showing the difference in vaginal pains during sexual intercourse between genitally mutilated women and those not genitally mutilated

\begin{tabular}{lcccccc}
\hline & $\mathrm{N}$ & $\bar{x}$ & $\mathrm{SD}$ & $\mathrm{df}$ & $\mathrm{T}$ & $\mathrm{P}$ \\
\hline Genitally mutilated & 106 & 8.77 & 3.62 & 109 & -1.523 & $>.05$ \\
Not genitally mutilated & 5 & 11.40 & 6.50 & & & \\
\hline
\end{tabular}

Hypotheses three, which states that genitally mutilated women and those not genitally mutilated will significantly differ in vaginal penetration experience during sexual intercourse, was not confirmed based on the result of $t$ test for independent samples in Table 11. The results showed the mean difference in the vaginal penetration experience of genitally mutilated women and those not genitally mutilated. No significance difference was found in the vaginal penetration experience of genitally mutilated women compared to those not genital mutilated [ $\mathrm{t}(109)=-1.523, \mathrm{P}>.05]$. This means that genital mutilation did not significantly influence women's vaginal penetration. This contradicted with the finding of Berg and Denision (2012) that women who have undergone FGM are more likely to experience painful intercourse than genitally mutilated women.

\subsection{Summary of Findings}

1. Genital mutilation did not significantly influence sexual satisfaction

2. Genital mutilation did not significantly influence sexual desire

3. Genital mutilation did not significantly influence women's vaginal penetration

\section{Conclusion}

This study attempts to ascertain the influence of genital mutilation on female sexual activities. The result of the hypotheses tested has been able to establish the persistence of the practice in Nigeria in-spite of several laws prohibiting its indulgence due to lack of scientific and positive reasons other than cultural beliefs which may no longer be tenable in contemporary societies. Thus, based on the establishment of a relationship which is not significant through the use of t-test for independent sample that genitally mutilated women will significantly differ in frequency of sexual satisfactions, desires, vaginal penetration compared to their non-genitally mutilated counterparts, the study concludes that female genital mutilation does not influence women sexual activities significantly.

\section{Recommendations}

Based on the above conclusion the study recommends thus:

a. The study recommends disrespect for the belief that genital mutilation influences sexual satisfaction among women.

b. The study also suggests disregard for the idea that genital mutilation influences sexual desire.

c. The study equally suggests ignoring the assumption that genital mutilation influences vaginal penetration during sexual intercourse.

By and large, genitally mutilated women should be sensitized on better ways to manage their lives to achieve better sexual activities or results.

\section{Acknowledgements}

The support of the Covenant University Centre for Research, Innovation and Development (CUCRID) in the course of this study is recognized 


\section{Reference}

Abasiekong, E. M. (2010). The Changing Faces of Rural Nigeria: Change and Continuity. Uyo: Abaam Pub.

Abia, A. A. (2012). African Beliefs systems and healthy living; International Journal of culture and human Development; vol: $4: 3$

Adetola, O.B. (2017): Social Change, Harmful Socialization Processes and the Future of Female Genital Mutilation in Abeokuta, Nigeria. Ibadan Journal of Sociology, 5): 47-72. www.ibadanjournalofsociology.org

Akinsulure-Smith A. M \& Chu T. (2017). Exploring Female Genital Cutting among Survivors of Torture. J Immigr Minor Health 2017; 19:769-73. 10.1007/s10903-016- 0419-x [PubMed] [Cross Ref]

Alsibiani, S \& Rouzi, A. A. (2008). Sexual Function in Women with Female Genital Mutilation, Fertility and Sterility, 93(3):722-4. DOI: 10.1016/j.fertnstert.2008.10.035

Banks E, Meirik O, Farley T, et al. (2006). Female genital mutilation and obstetric outcome: WHO collaborative prospective study in six African countries. Lancet; 367:1835-41

Bayeh, Joseph N.; Baltos, Georgios C. (2019). From a Culture of Borders to Borders of Cultures: Nationalism and the "Clash of Civilizations" in International Relations Theory. Journal of Educational and Social Research, 9(1): ISSN 2240-0524.

Behrendt A, Moritz S. (2005). Posttraumatic stress disorder and memory problems after female genital mutilation. Am J Psychiatry; 162:1000-2

Berg, R.C, Underland V, Odgaard-Jensen J, et al . (2014). Effects of female genital cutting on physical health outcomes: a systematic review and meta-analysis. BMJ Open2014; 4: e006316.

Berg, R. and Denision, E. (2012) Does female genital mutilation/ cutting (FGM/C) affect women's sexual functioning? A systematic review of the sexual consequences of FGM/C, Sexuality Research and Social Policy, 9(1), pp.41-56.

Bibeau, G., \& Corin, E. (1995). From submission to the text to interpretative violence. In G. Bibeau \& E. Corin (Eds.), Beyond sexuality. Asceticism and violence in anthropological interpretation. Approaches to semiotics series (pp. 3-54). Berlin, Germany: Mouton de Gruyter

Bonnie K. Nastasi, Prerna G. Arora \& Kris Varjas (2017) The meaning and importance of cultural construction for global development, International Journal of School \& Educational Psychology, 5:3, 137-140, DOI: 10.1080/21683603.2016.1276810

Cook, R. J, Dickens, B. M, Fathalla, M. F. (2002). Female genital cutting (mutilation/circumcision): ethical and legal dimensions. Int J Gynaecol Obstet; 79:281-7.

Frater, J. (2007). Top 10 Bizarre Traditions. Available on http://listverse.com/2007/08/12/top- 10-bizarretraditions/

Gage AJ, Van Rossem R. (2006). Attitudes toward the discontinuation of female genital cutting among men and women in Guinea. Int J Gynaecol Obstet; 92:92-6.A

George, T. O., Ozoya, M. I and Amos, E. O. (2017). Women in informal cross-border trading along Nigeria and Benin republic border: Challenges and coping strategies. International Journal of Applied Business and Economic Research, 15(26): 155-163

Haferkamp, H., \& Smelser, N. (Eds.) (1992). Social change and modernity, Berkeley Los Angeles: University of California Press

Hoiberg, Dale H., ed. (2010). "Abeokuta". Encyclopædia Britannica. I: A-ak Bayes (15th ed.). Chicago, IL: Encyclopædia Britannica Inc. p. 27. ISBN 978-1-59339-837-8.

Kizilhan, J. I. (2011). Impact of psychological disorders after female genital mutilation among Kurdish girls in Northern Iraq. Eur J Psychiat; 25:92-100.

Knipscheer, J., Vloeberghs, E., van der Kwaak, A., \& van den Muijsenbergh, M. (2015). Mental health problems associated with female genital mutilation. BJPsych bulletin, 39(6), $273-277$. doi:10.1192/pb.bp.114.047944

Koski, A and Heymann, J. (2017). Thirty-year trends in the prevalence and severity of female genital mutilation: a comparison of 22 countries. BMJ Global Health; 4(10)2: e000467. Doi:10.1136/bmjgh-2017-000467

Lee, C. H., Hung, C. C., Chien C. S., Zhuang, W. L and Hsu, C. Y. Y. (2017). Regulatory foci and expatriate adjustment. Personnel Review 46 (3): 512-525. https://doi.org/10.1108/PR-03-2015- 0077

Mimiko, N.O. (2010). "Would Falola Frustrations Suffice?: Tradition, Governance Challenges and the Prospects of Change in Africa" in Niyi Afolabi, ed. Toyin Falola: The Man, The Mask, The Muse. North Carolina: Carolina Academic Press.

Mohammed, E. H., Dandash; G. L. K., Refaat, A and Eyada, M. (2001) Female Genital Mutilation and its Psychosexual Impact. Journal of Sex and Marital Therapy 27(5):465-73. DOI: 10.1080/713846810

Nastasi, B. K., \& Hitchcock, J. (2016). Mixed methods research and culture-specific interventions: Program design and evaluation The New Mixed Methods Research Series. Thousand Oaks, CA: Sage

National Population Commission (2006). 2006 Census. National Population Commission, Abuja 
Odukogbe, A.-T. A., Afolabi, B. B., Bello, O. O., \& Adeyanju, A. S. (2017). Female genital mutilation/cutting in Africa. Translational Andrology and Urology, 6(2), 138-148. http://doi.org/10.21037/tau.2016.12.01

Ojua, T. A. \& Omono, C. (2012). African Sacrificial ceremonies and issues in socio-cultural Development. British Journal of Arts and Social Development, 4: 1.

Ojua, T. A., Ishor, D. G and Ndom, P. J. (2013). African Cultural Practices and Health Implicationsfor Nigeria Rural Development. International Review of Management and Business Research, 2(1): 176-183

Olu-Olu, O. and Jegede, L. I. (2014). Redressing security and crime in Nigeria through traditional Yoruba social values and cultural practices. Developing Country Studies, 4(4): 52-57.

Oluwunmi, A. O., Emeghe, I. J., Oluwadamilola, A., Fulani, O., Peter, N. J and Akinjare, O. A. (2017). Gender inequality and women discrimination in the real estate firms in Lagos State, Nigeria Proceedings of the 29th International Business Information Management Association Conference - Education Excellence and Innovation Management through Vision 2020: From Regional Development Sustainability to Global Economic Growth; 4367-4377. Vienna; Austria; 3 May 2017 through 4 May 2017; Code 129797

Omonijo, D. O., Olujobi, O. J., Anyaegbunam, M. C., Nnatu, S. O and Adeleke, V. A. (2018). Fundamental human rights, polices of a Nigerian private mission university and the safety of students: Critical analysis, Journal of Social Sciences Research, 4(12): 841- 848

Osinowo, H. O \& Taiwo, A. O. (2003). Impact of Female Genital Mutilation on Sexual Functioning, Self-Esteem and Marital Instability of Women in Ajegunle. (IFE PsychologIA, 11 (1): 123-130. http://dx.doi.org/10.4314/ifep.v11i1.23446

Pauliene, R., Diskiene, D \& Matuzeviciute, E. (2019). Complex Approach on Multicultural Teams Management \& Leadership. Journal of Educational and Social Research, 9(2): 8-16. Doi: 10.2478/jesr-2019-0008

Rosen, R., Brown, C., Heiman, J., Leiblum, S., Meston, C., Shabsigh, R \& Ferguson, D. (2000). The Female Sexual Function Index (FSFI): A Multidimensional Self-Report Instrument for the Assessment of Female Sexual Function. Journal of Sex \& Marital Therapy, 26:191-208. 0092-623X/00 \$12.00+.00

Shabila, N. P., Saleh, A. M., \& Jawad, R. K. (2014). Women's perspectives of female genital cutting: Qmethodology. BMC women's health, 14, 11. Doi:10.1186/1472-6874-14-11

Teixeira, A. L \& Lisboa M. (2016). Estimating the prevalence of female genital mutilation in Portugal. Public Health; 139:53-60. 10.1016/j.puhe.2016.05.002 [PubMed] [Cross Ref]

United Nations Population Funds (2016). Female genital mutilation (FGM) frequently asked questions. Accessed on: July 28, 2016. Available online: http://www.unfpa.org/resources/female-genital-mutilationfgm-frequently-asked- questions\#sthash.ILBanQT3.dpuf. [Ref list]

Valsiner, J. (2000). Culture and Human Development. London, England: Sage.

Yamane, Taro. 1967. Statistics, an Introductory Analysis, 2nd Ed., New York: Harper and Row. 